\title{
Welcome to the CAG national office!
}

W elcome to 2902 South Sheridan Way, Oakville, Ontario - the Canadian Association of Gastroenterology (CAG) national office. Under the same roof as Pulsus Group, publisher of The Canadian Journal of Gastroenterology, the CAG national office consists of substantial space on the second floor of the building. The national office includes the office

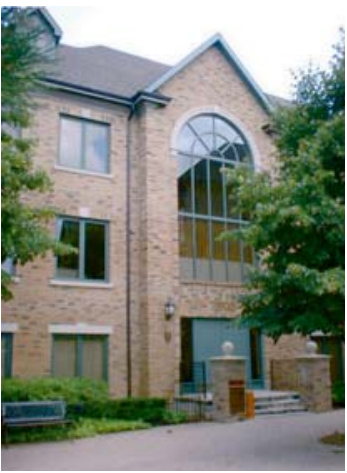
of the executive director, a part-time assistant and adequate boardroom facilities to accommodate meetings of up to 12 people. If you are in the area, please drop by - we will be glad to show you around!

You may already have spoken with Roisin Lundy. She

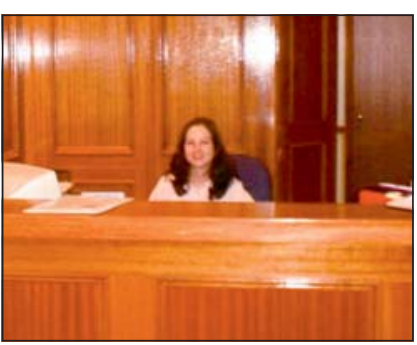
runs the front end of the national office, and her duties include daily administration, membership information and renewals, and fielding incoming questions and requests. Feel free to give her a call if we can be of assistance. Don't forget, you can now call toll free at 888-780-0007!
In the back end of the office is me, Paul Sinclair, your new executive director of CAG. I have spent several years working in the gastroenterology community from the pharmaceutical side. I look forward to continued communication with the Canadian gastroenterology community. First

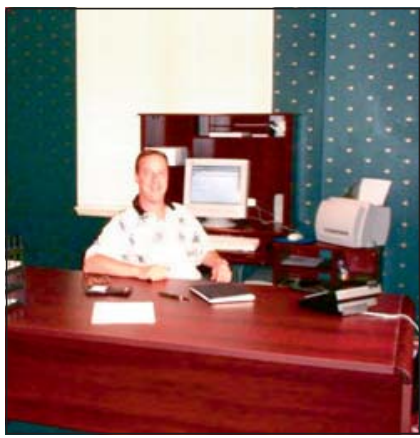
and foremost, it is important that you understand the mandate of the national office, which is to serve the membership under the direction of the CAG executive. The CAG is poised to make major advances in many areas, including further research investment and partnership, education and maintenance of certification to name a few. We have already set a baseline strategic plan to take the CAG forward over the next three to five years - all components of the plan focus on benefit to the customer, be it you, the CAG member, the pharmaceutical industry member or the patient.

The national office is your window to the CAG executive; so don't hesitate to contact us directly with questions, comments or concerns. We are here to serve the membership, help develop strategies for the future, and ensure implementation, completion and ultimately growth of the organization over the years to come. 


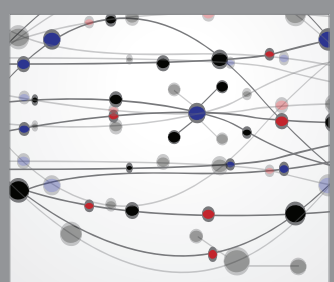

The Scientific World Journal
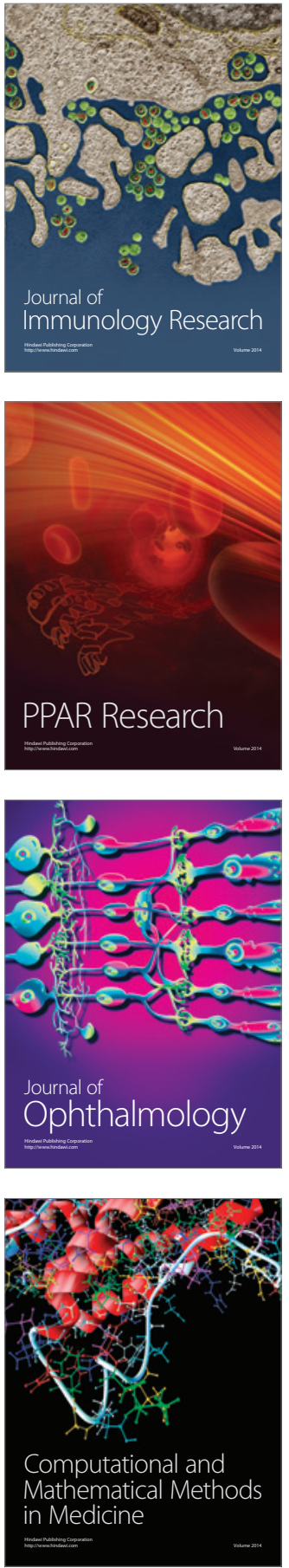

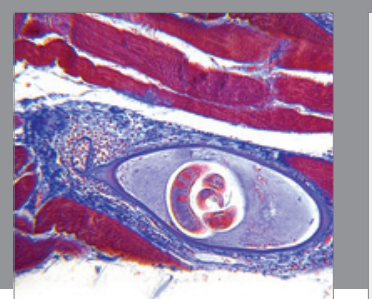

Gastroenterology Research and Practice

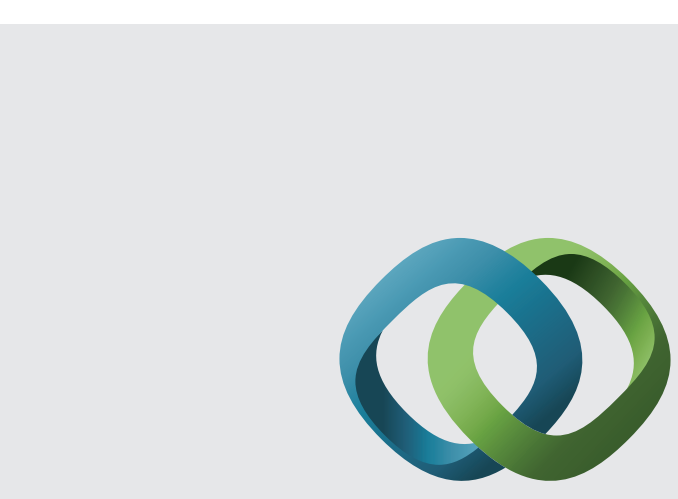

\section{Hindawi}

Submit your manuscripts at

http://www.hindawi.com
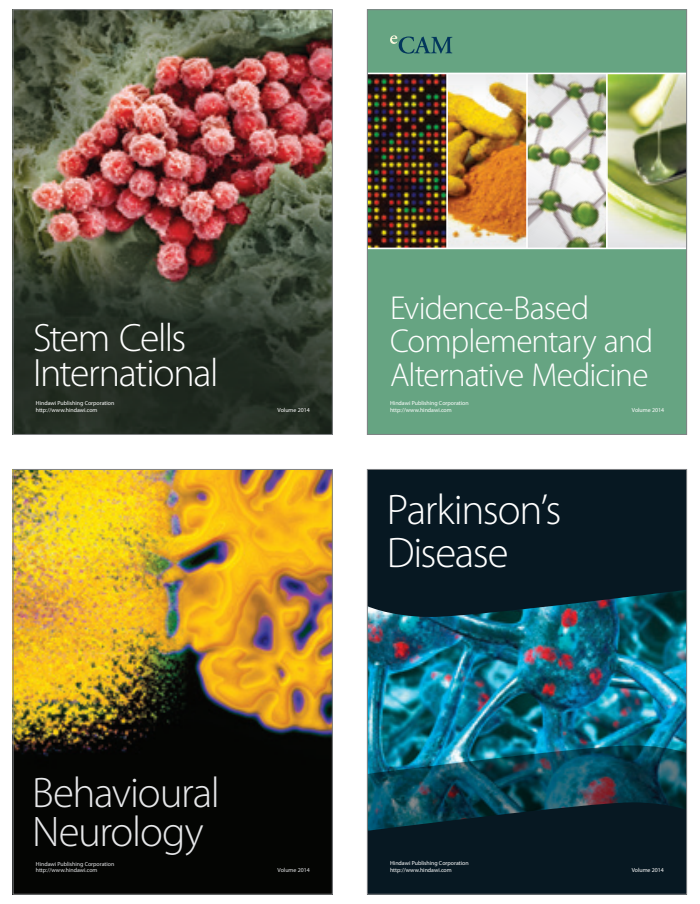
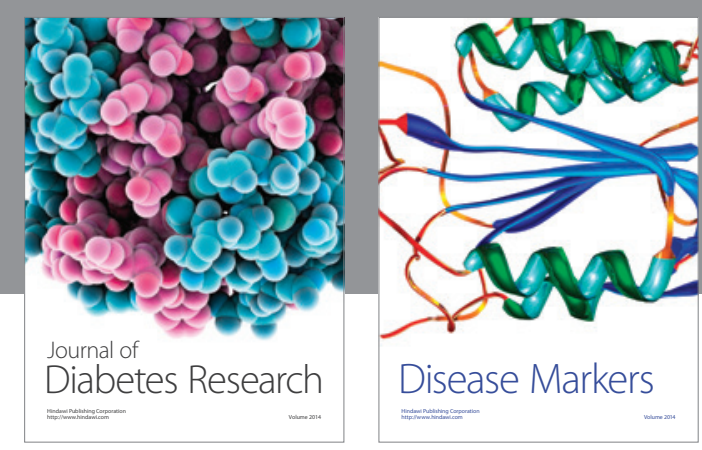

Disease Markers
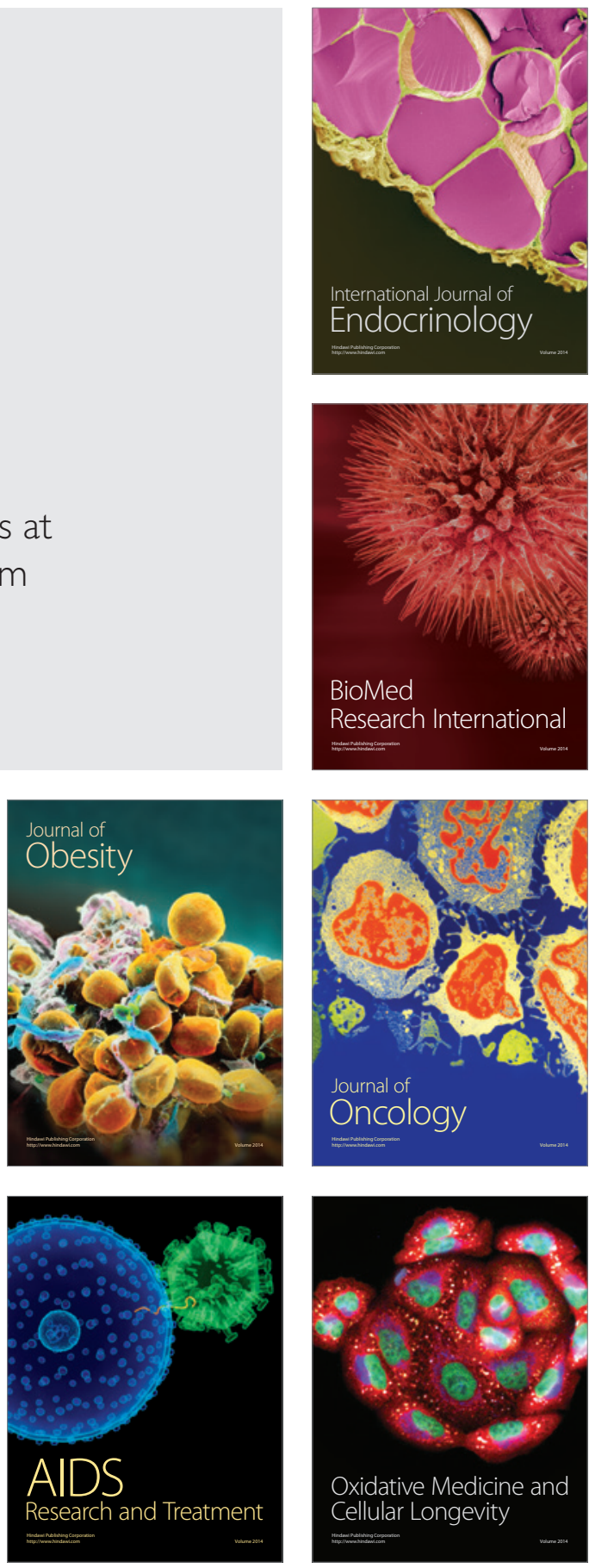